\title{
Escalpe lipedematoso com início precoce
}

\author{
Lipedematous scalp with early onset
}

\author{
Roberto Rheingantz da Cunha Filho ${ }^{1}$ \\ André Cartell ${ }^{3}$
}

Hiram Larangeira de Almeida $\mathrm{Jr}^{2}$

\begin{abstract}
Resumo: Escalpe lipedematoso é uma rara doença de origem desconhecida, caracterizada pelo aumento amolecido do couro cabeludo. Apresentamos um caso em paciente feminina de 13 anos de idade, com espessamento amolecido do vértex, prurido e crescimento lento dos fios na região afetada. O anatomopatológico revelou edema, infiltrado mononuclear esparso e perifolicular discretos, vasos linfáticos ectásicos e aumento do tecido subcutâneo, o qual foi ratificado pela ultrassonografia. Este é o segundo relato antes dos 18 anos de idade.

Palavras-chave: Couro cabeludo; Edema; Tecido subcutâneo

Abstract: Lipedematous scalp is a rare disease of unknown cause characterized by increased scalp thickness with a soft consistence. We report the case of a 13-year-old female with pruriginous soft thickening of the scalp vertex and slow growth of hair in the affected area. Anatomopathological examination showed edema, sparse mononuclear inflammatory perifollicular infiltrate, and ectatic lymphatic vessels. Ultrasonography confirmed thickening of the subcutaneous tissue. This is the second report of the disorder in a patient younger than 18 years old.

Keywords: Edema; Scalp; Subcutaneous tissue
\end{abstract}

\section{INTRODUÇÃO}

Escalpe lipedematoso (EL) é uma alteração extremamente rara de origem desconhecida, caracterizada pelo espessamento edematoso, de consistência amolecida e não tumoral do couro cabeludo, sendo mais palpável do que visível. Alopecia lipedematosa (AL) é quadro semelhante, associado com hipotricose ou encurtamento dos fios. Não há consenso, mas podem ser espectros da mesma doença. ${ }^{1}$ Documentase caso raro, de início precoce, com estudo histológico e ultrassonográfico, sendo o primeiro na América Latina.

\section{RELATO DE CASO}

Paciente feminina, parda, estudante, 13 anos de idade, apresenta espessamento progressivo do vértex do couro cabeludo, mais palpável do que visível, com evolução de um ano, por vezes pruriginoso, referindo crescimento mais lento dos fios na região afetada - a qual foi tricotomizada para documentação fotográfica e para a realização da biópsia (Figura 1). Os cabelos na área afetada eram discretamente mais curtos, todavia não foram evidentes cabelos mais finos ou hipotricose. A menarca ocorreu aos 11 anos. Nega trauma prévio e história familiar de casos seme-

\footnotetext{
Recebido em 20.03.2009.

Aprovado pelo Conselho Consultivo e aceito para publicação em 31.07.09

* Trabalho realizado em clínica particular de Joaçaba (SC) e na Universidade Católica de Pelotas (UCPel) - Pelotas (RS), Brasil. Conflito de interesse: Nenhum / Conflict of interest: None

Suporte financeiro: Nenhum / Financial funding: None

Mestre em saúde e comportamento pela Universidade Católica de Pelotas (UCPel) - Pelotas (RS), Brasil. Médico dermatologista em clínica particular em Joaçaba (SC), Brasil.

Doutor em dermatologia, professor e coordenador do programa de pós-graduação em saúde e comportamento, Universidade Católica de Pelotas (UCPel) Professor de dermatologia da Universidade Católica de Pelotas (UCPel) e da Universidade Federal de Pelotas (UFPel) - Pelotas (RS), Brasil.

Dermatopatologista e professor de patologia da Universidade Federal do Rio Grande do Sul (UFRGS) - Porto Alegre (RS), Brasil

(C)2010 by Anais Brasileiros de Dermatologia
} 


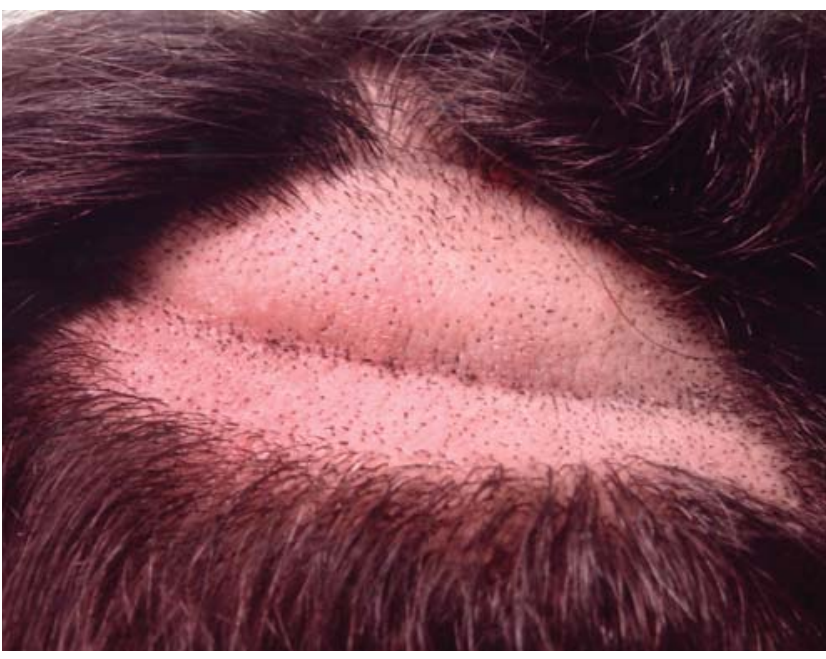

Figura 1: Área afetada do vértex tricotomizada mostra aumento de partes moles com pregueamento ou sulco

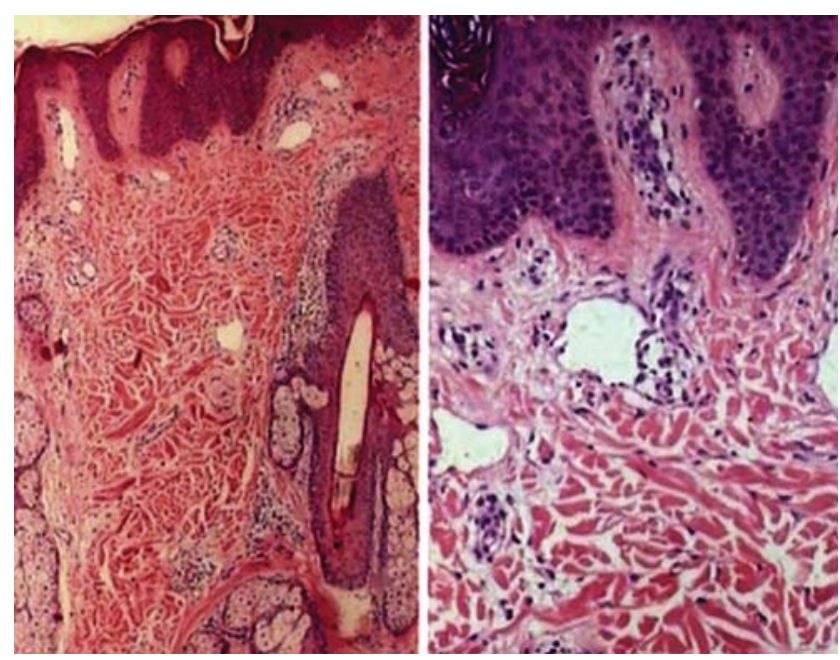

Figura 2: Exame anatomopatológico em pequeno aumento evidencia infiltrado inflamatório perifolicular focal e edema discretos (coloração hematoxilina e eosina - HE, 40x). Em maior aumento, verificam-se vasos linfáticos ectásicos (HE, 100x)
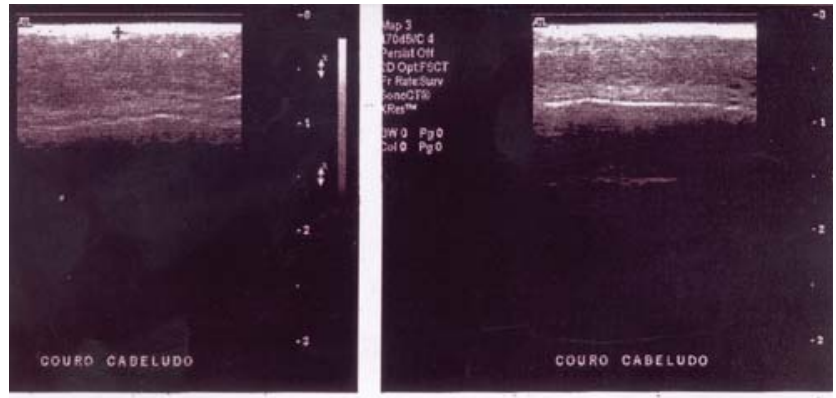

tâneo, variando de $6,2 \mathrm{~mm}$ a $9,1 \mathrm{~mm}$ - em indivíduos normais esperam-se entre 5 e $6 \mathrm{~mm}$ para a região do vértex (Figura 3).

\section{DISCUSSÃO}

Há cerca de 30 casos relatados no mundo de EL e AL, sendo a maior parte de AL. A idade varia entre nove e 77 anos, sem predomínio de raça, havendo apenas um relato em paciente masculino. Em ordem de frequência há prurido, ausência de sintomas, dor, irritação e parestesia. ${ }^{1,2}$ As associações descritas são com nevo lipomatoso superficial e pele hiperelástica, atingindo preferencialmente o vértex e a região parietal. ${ }^{3}$ A medida do escalpe pode ser realizada por ultrassonografia, ressonância magnética, tomografia ou por agulha. ${ }^{4} \mathrm{O}$ caso que relatamos está de acordo com a literatura; entretanto, tem início precoce, sendo o segundo caso antes dos 18 anos de idade. ${ }^{5}$ Classifica-se mais adequadamente como EL, apesar da queixa de os cabelos crescerem mais lentamente e aparentarem ser um pouco mais curtos na região atingida.

A etiologia é desconhecida, mas há suspeita de fatores hormonais pelo predomínio absoluto em mulheres. A microscopia óptica é inespecífica, poden-
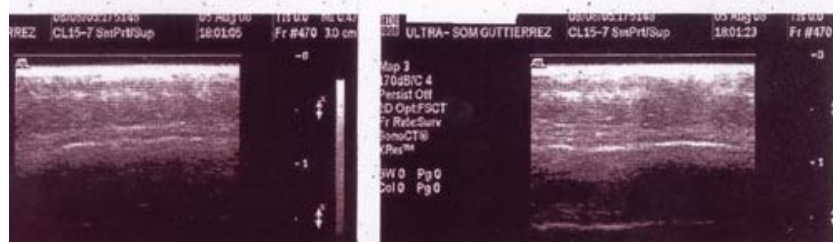

FigURA 3: Imagem ultrassonográfica mostra espessamento do subcutâneo da região do vértex

do ser discreta, incluindo edema, aumento do subcutâneo, hiperqueratose, infiltrado inflamatório esparso, perifolicular ou perivascular, alterações foliculares, edema, vasos linfáticos ectásicos e redução do número de folículos, sendo aconselhada correlação anátomo-clínica. Fibras elásticas são preservadas. Estudos podem ser realizados na tentativa de esclarecer a fisiopatogenia, incluindo os sintomas associados. Produção e liberação de mediadores químicos e citocinas devem ser abordadas nessas pesquisas. ${ }^{6,7}$

O tratamento é desafiador por ser doença bastante rara, e os relatos, na maioria, não citam intervenções. Há um relato de melhora com corticoide sistêmico. 


\section{REFERÊNCIAS:}

1. El Darouti MA, Marzouk SA, Mashaly HM, El Nabarawi EA, Abdel-Halim MR, El Komy MM, et al. Lipedema and lipedematous alopecia: report of 10 news cases. Eur J Dermatol. 2007:17;351-2.

2. Martín JM, Monteagudo C, Montesinos E, Guijarro J, Llombart B, Jordá E. Lipedematous scalp and lipedematous alopecia: a clinical and histologic analysis of 3 cases. J Am Acad Dermatol. 2005:52;152-6.

3. Mansur AT, Yasar S, Aydingöz IE, Göktay F, Ozdemir N, Sungurlu F. Colocalization of lipematous scalp and nevus lipomatosus superficialis: a case report. J Cutan Pathol. 2006;34:342-5.

4. Yasar S, Mansur AT, Göktay F, Sungurlu F, Vardar Aker F, Ozkara S. Lipedematous scalp and lipedematous alopecia: report of three cases in white adults. J
Dermatol. 2007:34;124-30.

5. Rowan DM, Simpson A, Wong KP. Lipedematous scalp in child. Pediatr Dermatol. 2006;23:276-8.

6. Scheufler O, Kania NM, Heinrichs CM, Exner K. Hyperplasia of the subcutaneous adipose tissue is the primary histopathologic abnormality in lipedematous scalp. Am J Dermatopathol. 2003;25:248-52.

7. Kavak A, Yuceer D, Yildirim U, Baykal C, Sarisoy HT. Lipedematous scalp: a rare entity. J Dermatol. 2008;35:102-5.

8. González-Guerra E, Haro R, Angulo J, Del Carmen Fariña M, Martín L, Requena L. Lipedematous alopecia: an uncommon clinicopathologic variant of nonscarring but permanent alopecia. Int $J$ Dermatol. 2008:47;605-9.

ENDEREÇO PARA CORRESPONDÊNCIA / MAILING ADDRESS

Roberto Rbeingantz da Cunba Filbo

Rua Roberto Trompowsky, 194, - Centro

89600000 Joaçaba, SC

Tel./fax: 49 3522-1269

E-mail: robertodermatologista@yaboo.com.br

Como citar este artigo/How to cite this article: Cunha Filho RR, Almeida Jr HL, Cartell A. Escalpe lipedematoso com início precoce. An Bras Dermatol. 2010;85(1):81-3. 